\title{
STUDENT SATISFACTION WITH DIGITAL HYBRID LEARNING IN EUROPEAN AND ORIENTAL LANGUAGES PROGRAMS: SURVEY STUDY OF REGIONAL UNIVERSITIES OF UKRAINE
}

\author{
Rusudan Makhachashvili and Ivan Semenist \\ Borys Grinchenko Kyiv University, 18/2, Bulvarno-Kudryavska-st., Kyiv Ukraine
}

\begin{abstract}
The global pandemic and subsequent quarantine measures and restrictions have posed an array of challenges to the structure and procedure of higher education workflow, which influenced significantly the scope of individual experiences, projected outcomes, and estimated quality of higher education in countries across the world. This study focus is the in-depth assessment of individual digital distance and blended learning experiences by students of different tiers (Bachelor's level, Master's level, Graduate school level) in European (French, Italian, Spanish, English, German) and Oriental (Mandarin Chinese, Japanese) Languages university level programs in regions of Ukraine through the span of educational activities in the time-frame of COVID-19 quarantine measures of March 2020 to January 2021. The survey and analysis of different ICT tools is used to assess the parameters and challenges of individual quality and efficiency of translation of the real-life Foreign Languages Acquisition practices into a digital blended format, involving activation of interdisciplinary skills and cross-sectorial activities, assisted by ICT tools. The online survey of 14 universities in regional centers of Ukraine provides for disclosure of student satisfaction with digitalized foreign languages education, systematized individual experiences, and quality estimation of e-learning and hybrid learning in the framework of COVID-19 lockdown; assessment of individual experiences and quality of e-learning and hybrid learning in the framework of COVID-19 lockdown as compared to traditional, face-to-face learning formats for foreign languages; individual quality assessment of learning process design, programmed learning outcomes and projected competencies for university programs of Oriental and European languages in the framework of COVID-19 lockdown and quarantine measures.
\end{abstract}

\section{KEYWORDS}

Hybrid Learning, e-Learning, Student Satisfaction, Oriental Languages, European Languages, Survey Study

\section{INTRODUCTION}

The global pandemic of COVID-19 emerged as a kind of a black swan scenario or a singularity (event horizon) (Tu 1994) for interdisciplinary domains of social and economic life, including education. The black swan theory is a concept that describes an event that comes as a surprise, has a major effect on society, and is often inappropriately rationalized after the fact with the benefit of hindsight (Taleb 2010).

In the educational domain, according to our estimations, the result of fundamental technological shift, induced by the COVID-19 pandemic development and enhanced by subsequent digitalization measures, was the need to take quick comprehensive action (Makhachashvili, Semenist et al 2020) in order to achieve such desirable results: a) to adapt the existent educational scenarios to digital, remote and blended formats; b) to activate complex interdisciplinary skillsets, otherwise latent or underutilized in the educational process; c) to boost ICT competence and digital literacy of all participants of the educational process relocated to computer being.

The global pandemic and subsequent quarantine measures and restrictions have posed an array of challenges to the structure and procedure of higher education workflow, which influenced significantly the scope of individual experiences, projected outcomes and estimated quality of higher education in countries across the world. 
Foreign Languages Acquisition at university level major programs is a rigorous process (Law OHE 2019) that involves different stages and a regimen of activities and competencies across interconnected interdisciplinary domains. The presented study is a parcel of comprehensive institutional inquiry into the toll digitalization and amplified use of ICT tools put on different aspects of Oriental (Mandarin Chinese and Japanese) as well as European (Italian, Spanish, French, English) languages acquisition efficiency, assessment management, programmed results, communicative and digital competency formation in COVID-19 lockdown paradigm.

The research project to date spans the following areas: 1) full survey datasets on ICT enhanced Final Qualification Assessment protocols for Oriental languages (Mandarin Chinese and Japanese) and European Languages (Italian, Spanish, French, English) major programs in Ukraine, Germany and India; 2) full survey datasets on multidisciplinary, cross-sectorial and universal skills development for Oriental languages (Mandarin Chinese and Japanese) and European Languages (Italian, Spanish, French, English) major programs in Ukraine; 3) full survey datasets on in-depth subjective experiences of e-learning and blended learning in COVID-19 timeframe for stakeholders of Oriental languages (Mandarin Chinese and Japanese) and European Languages (Italian, Spanish, French, English) major programs in the capital city and regional universities of Ukraine.

The accumulated data so far has been seminal for a range of publications (Makhachashvili, Semenist, et al 2020; Makhachashvili, Semenist, Bakhtina 2020), covering the issues of ICT tools efficiency rating regimen for foreign languages programs, isolated and comparative case studies of Oriental and European languages acquisition digitization procedures and best practices.

The estimations of digital distant education quality, conducted across various studies in the pre-COVID-19 inquiry framework have spanned, among others, assessment of satisfaction with distance learning experience (Bekele 2010; Bolliger 2009); the added value of online learning (Thiessen, Ambrock 2011); evaluation of learning outcomes (Costareie 2011; Ni 2013); overall attitudes to distance learning (Salyers et al 2014); challenges of online education (Markova et al 2017), networking principles in e-learning (Smyrnova-Trybulska, Kommers et al 2019). These issues require a comprehensive revisit in terms of the toll the global pandemic took on individual learning experiences and subsequent shift in quality estimations of linguistic education in universities due to the abrupt transition to exclusively distant, digital distant or hybrid learning formats as a mode of formal education and university degree acquisition (as opposed to being a mostly auxiliary learning method or an informal learning format).

This study objective, henceforth, is to critically review the satisfaction parameters via in-depth assessment of individual digital distance and hybrid learning experiences and best practices by students of Oriental (Mandarin Chinese, Japanese) and European (French, Italian, Spanish, English, German) Languages university level programs in regions of Ukraine (Eastern Europe) through the span of educational activities in the time-frame of COVID-19 quarantine measures of March 2020 to January 2021. The survey and analysis of different ICT tools is used to assess the parameters and challenges of individual quality and efficiency of translation of the real-life Foreign Languages Acquisition practices into the digital blended format, involving activation of interdisciplinary skills and cross-sectorial activities, assisted by ICT tools.

The study premise is based on identification of various digital distant learning formats (u-learning, m-learning, hybrid learning) (Crowe 2007) and modes for university educational programs and projected digital literacy requirements (EC 2020; DGR 2019; WEF 2020).

Within the parameters of this study, we estimate electronic learning (e-learning) as a form of ubiquitous learning (u-learning) that involves learning in an environment with full access to digital devices and services at any given moment (Van't Hooft 2007).

COVID-19 quarantine measures, put in place country-wide in educational institutions of Ukraine in the time spans of March-June 2020, October-December 2020, and January 2021 have demanded the simultaneous employment and overlap of the following digital learning formats: e-learning 1.0 (direct synchronous computer-assisted distant instruction); e-learning 2.0 (mostly asynchronous computer-supported collaborative learning, also known as "networked collaborative learning") (Trentin 2010); blended learning (in-person teaching with asynchronous ICT assisted learning methods) (Voorn, Kommers, 2013; Dos Reis 2015; Boyarsky 2020); hybrid learning (synchronous instruction of in-presence and remote students via ICT tools) (Duff 2020).

Based on the level of quarantine alert, adopted in regions of Ukraine e-learning 1.0/2.0 (for red and orange zones of quarantine) and hybrid learning (for yellow zones) formats were implemented. 


\section{DIGITAL DISTANT AND HYBRID LEARNING STUDENT SATISFACTION: SURVEY RESULTS}

\subsection{Method Overview}

The study employs the combination of mixed methods (Almalki 2016) - a proportional arrangement of quantitative and qualitative inquiry to assess in-depth aspects of subjective and individual quality estimation of digital distance and hybrid learning. The comprehensive study design methodology included the following consecutive steps: 1) distance digital learning activity, experience, and application profiling; 2) The online survey method - based on D. Dillman's concept of mixed-media and mixed-mode surveys (Dillman 2014) applied to conduct an in-depth assessment of individual digital distance and blended learning experiences and practices by relevant groups of stakeholders in Oriental and European Languages university level programs in regions of Ukraine; 3) digital content analysis of individual associations with different modes of learning by relevant groups of stakeholders in Oriental and European Languages university level programs in regions of Ukraine (via corpus and text-mining tools); 4) digital distance and blended learning models and procedures adaptation and customization, tailored to the individual and group needs of stakeholders in Foreign Language Acquisition on the university level.

\subsection{Instrument}

Based on the activity profile (digital distance and blended learning in Foreign Language Acquisition) an online survey was devised to assess in-depth subjective experiences of e-learning and hybrid learning in the COVID-19 timeframe (March 2020 - January 2021) for students of Oriental languages (Mandarin Chinese and Japanese) and European Languages (Italian, Spanish, French, English) major programs.

The online questionnaire comprised of 21 questions total (multiple choice, ranking/scoring and open-end/short answer types), divided into such categories: 1) questions on overall assessment of individual experiences and quality estimation of e-learning and hybrid learning in the framework of COVID-19 lockdown and quarantine measures (March 2020 - January 2021) for university programs of Oriental (Mandarin Chinese, Japanese) and European (English, French, Spanish, Italian) and languages; 2) questions on assessment of individual experiences and quality of e-learning and hybrid learning in the framework of COVID-19 lockdown as compared to traditional, face-to-face learning formats; 3) questions on individual quality assessment of learning process design, programmed learning outcomes and projected competencies for university programs of European (English, French, Spanish, Italian) and Oriental (Mandarin Chinese, Japanese) languages in the framework of COVID-19 lockdown and quarantine measures (March 2020 January 2021).

\subsection{Data Gathering}

A sizable sample of 507 respondents total across Oriental (Mandarin Chinese, Japanese) and European (English, French, Spanish, Italian) languages in universities of the capital city and regional universities of Ukraine took part in the survey.

The following groups of stakeholders of the digital distant education in the timespan of COVID-19 pandemic measures were respondents of the survey overall in regions of Ukraine (Figure. 1): Students of Bachelor's programs for Oriental (Mandarin Chinese, Japanese) and European (English, French, Spanish, Italian) languages (1st, 2nd, 3rd and 4th years of study) - 94.3\%; Students of Master's programs for Oriental (Mandarin Chinese, Japanese) and European (English, French, Spanish, Italian) languages (1st and 2nd years of study) - 3.8\%; Students of Post-graduate programs for Oriental (Mandarin Chinese, Japanese) and European (English, French, Spanish, Italian) languages (1st, 2nd, 3rd and 4th years of study) $-1.9 \%$.

The survey sample geographic distribution covers the universities of the capital city of Ukraine (Kyiv) (3 universities) and a representative selection of regional universities of Ukraine (14 universities), offering major programs in Oriental (Mandarin Chinese, Japanese) and European (English, French, Spanish, Italian) languages on all three tiers of educational levels according to the legislature of Ukraine (Law OHE 2019): undergraduate, graduate and post-graduate. The survey was deployed in the timespan of December 2020 
through January 2021, which corresponds to the coverage of two full semesters of quarantine measures in universities of Ukraine.

The regional parameters of the assessed universities allow to estimate student satisfaction through individual experiences and quality of e-learning and hybrid learning in the framework of COVID-19 lockdown across foreign languages programs in the capital city (Kyiv), 9 regional city-centers of Ukraine (Kharkiv, Dnipro, Zaporizhzhya, Kropyvnytskyi (Kirovohrad), Kherson, Odessa, Chernivtsi, Lviv, Lutsk) and 3 regional cities of Ukraine (Mariupol, Kryviy Rih, Dneprodzerzhinsk). The geographic distribution of the sample allows to feature all regions of Ukraine - North, East, South, and West.

For the purposes of this study, the survey results were scaled to feature students of Oriental (Mandarin Chinese, Japanese) and European (English, French, Spanish, Italian) languages programs of 14 regional universities of Ukraine (excluding the capital city - Kyiv) to estimate the parameters and challenges of the individual experiences and quality assessment of e-learning and hybrid learning in the framework of the COVID-19 lockdown, common for higher educational institutions of the regional scale and status.

\subsection{Survey Results}

Group 1 of survey questions - an overall assessment of individual experiences and quality estimation of e-learning and hybrid learning in the framework of COVID-19 lockdown and quarantine measures (March 2020 - January 2021) for university programs of European (English, French, Spanish, Italian) and Oriental (Mandarin Chinese, Japanese) languages- yielded the following representative results across the board.

The assessment of overall comprehensive individual experience (or a take-away) of e-learning and hybrid learning in the framework of COVID-19 lockdown by different groups of stakeholders was conducted according to the 5-Point Likert Scale (a response scale in which responders specify their level of engagement with a statement or a parameter in five points: (1) Strongly disagree; (2) Disagree; (3) Neither agree nor disagree; (4) Agree; (5) Strongly agree [19]. The extremum points for evaluation were 1 (maximum negative overall experience of e-learning and hybrid learning) and 5 (maximum positive overall experience of e-learning and hybrid learning).

Students of European and Oriental languages programs of all levels in regional universities of Ukraine evaluated their comprehensive individual experience of e-learning as predominantly 4 - mostly agreeable (34.3\% of respondents), 3 - Average (30.6\%), 5 - most agreeable $-21.3 \%$.

Qualitative assessment of the e-learning and hybrid learning was conducted through the retrospective evaluation of respondents' individual experience through the span of March 2020 to January 2021, in order identify and select the preferred features and elements of e-learning and hybrid learning among the following: Ability to work from home; Ability to customize of the study space (video conferencing or LMS); Adaptability and flexibility of the work schedule; Save time for commute; Parallel performance of several tasks and activities; Opportunity to technologically diversify educational activity, educational materials and methods; Ability to adapt the structure and content of curricula of disciplines to the conditions of online learning; Ability to activate and improve different types of soft skills; Opportunity to improve digital literacy; Ability to work independently in the learning process; No need for constant interpersonal communication; Ability to engage international professionals through digital means.

The quantitative assessment demonstrated that students of European and Oriental languages programs of all levels in regional universities of Ukraine have distributed preferred features and elements of e-learning and hybrid learning (Figure 1) and identified the significantly top-ranking ones as follows: 


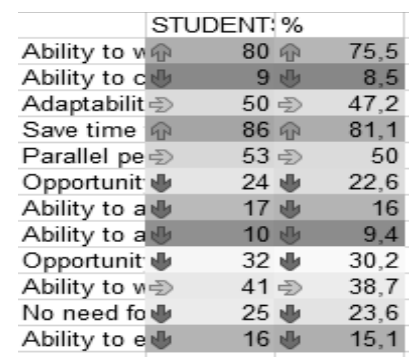

- $\quad$ Ability to work from home -

- $\quad$ Parallel performance of several tasks and activities -

- $\quad 75.5 \%$ of respondents;

- $\quad 50 \%$ of respondents;

- $\quad$ Adaptability and flexibility of the work schedule -

- $\quad$ Ability to work independently in the learning process

- $\quad 47.2 \%$ of respondents;

- $\quad 38.7 \%$ of respondents.

Figure 1. Distribution of preferred features and elements of e-learning and hybrid learning

Evaluation of respondents' individual experience through the span of March 2020 to January 2021 allowed to identify and select the features and elements of e-learning and hybrid learning, considered drawbacks, challenges or a hindrance among the following: Forced need to work at home (uncomfortable living conditions); Impossibility / difficulty of adaptation and flexibility of the work schedule; The need for specialized technical means of training and online communication / technical limitations; Lack of interpersonal communication with students and colleagues on a regular basis; Emotional burnout; The need to activate and improve different types of soft skills; The need to improve digital literacy; Increasing the amount of workload in preparation for training sessions and ensuring the learning process; The need to adapt the structure and content of curricula of disciplines in terms of online learning; The need to organize and control the independent work of students; Availability of mechanisms for control and accounting of the educational process.

Students of Oriental and European languages programs of all levels in regional universities of Ukraine have distributed drawback features and elements of e-learning and hybrid learning and identified the top-ranking ones. Top scoring features and elements of e-learning and hybrid learning, considered drawbacks, challenges or a hindrance by all groups of students of Oriental and European languages programs of all levels in regional universities of Ukraine are: Increased amount of workload in preparation for training sessions (63.9\% of respondents); Emotional burnout (54.6\%); Lack of interpersonal communication on a regular basis $(47.4 \%)$; The need for specialized technical means of training and online communication / technical limitations $(32 \%)$.

The following crucial elements of educational process design were identified and selected by respondents across all groups and Foreign Language Programs: Conducting lectures; Conducting practical classes; Development of training materials and materials for assessment; Execution of tasks (volumes, format, method of presentation); Organization of group work of students; Organization of independent work of students; Organization of creative work of students; Organization of research work; Communication with students (current); Communication with students (advisory); Informal communication outside the learning process / mentoring and moderation; Assessment (formative, summative, qualification).

Each element of the educational process was subjected to a ranking by all groups of students according to the 5-Point Likert Scale in terms of its efficiency for e-learning and hybrid learning quality assurance (Figure 2):

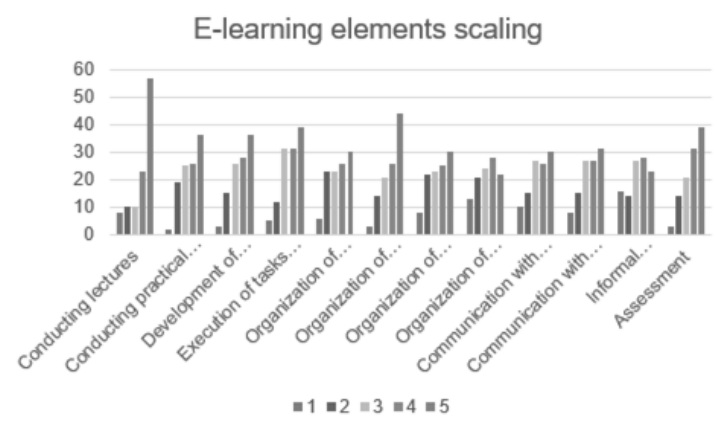

Figure 2. Elements of educational ranking in terms of efficiency for e-learning quality assurance 
Students of Oriental and European languages programs of all levels in regional universities of Ukraine have identified the following elements of the educational process and management as ranking highest (5 - most conductive for quality of e-learning and hybrid learning in individual experience): Conducting lectures (52\% of respondents); Organization of group work of students (42\%); Summative assessment (38\%); Organization of independent work of students (29.5\%); Communication with students (current) (29.5\%).

The following elements of the educational process and management were identified as ranking $2^{\text {nd }}$ highest by all groups of students (4 - mostly conductive for quality of e-learning and hybrid learning in individual experience): Formative assessment (33.4\%); Execution of tasks (volumes, format, method of presentation) (29.1\%); Organization of research work (29\%); Conducting practical classes (27\% of respondents).

Respondents of Oriental and European languages programs of all levels in regional universities of Ukraine were asked to identify the e-learning and hybrid learning educational process elements that are conductive to quality of learning experiences outside of the COVID-19 framework and are preferable to be retained and implemented on a regular basis (Figure 3): Online classes through video conferencing systems; Online advisory sessions; Online implementation and defense of final / diploma projects; Use of electronic learning management system (LMS Moodle, Google Class etc.); Electronic tests and assessments online; Cloud technologies for collaboration; Cloud technologies for project presentation; Communication through electronic resources (mail, video, chat services, social networks); Use of e-textbooks and materials; Online interaction with the administration and methodological support; Time management; Possibility of study / research work at home or without binding to a place (ubiquitous learning); Ability to build an individual learning trajectory; Opportunity to utilize informal education resources.

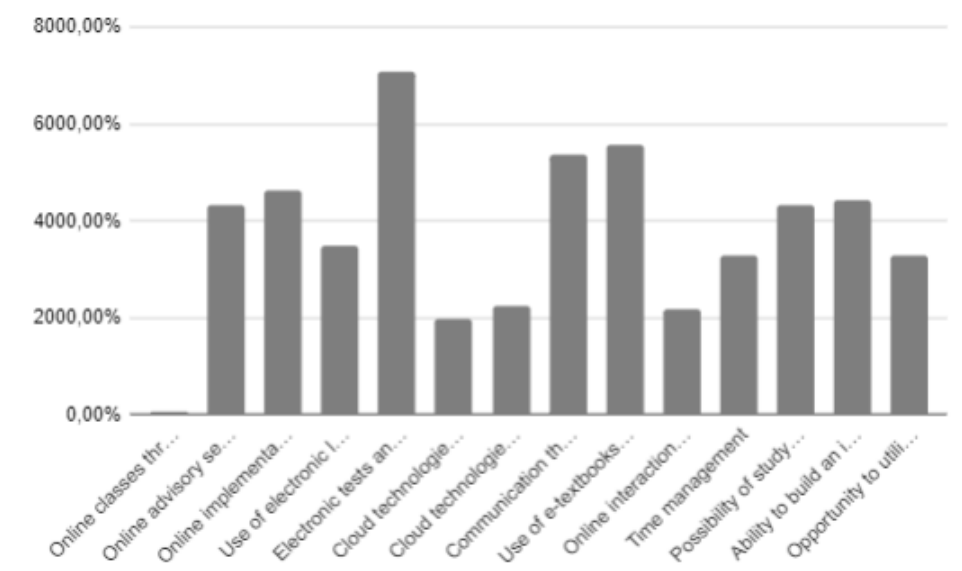

Figure 3. Elements that are conductive to quality of learning experiences outside of the COVID-19 framework: students survey

The following elements of hybrid and e-learning scored highest by students of European and Oriental languages programs in regional universities of Ukraine scored highest as desirable to be retained and further implemented in the educational process outside of the COVID-19 limitation measures:

- Electronic tests and assessments online -

- Use of e-textbooks and materials -

- Online classes through video conferencing systems

- Communication through electronic resources (mail, video, chat services, social networks)

- Online implementation and defense of final / diploma projects

- $\quad$ Ability to build an individual learning trajectory

- $\quad$ Ubiquitous learning -

- $\quad 70.8 \%$ of respondents

- $\quad 55.7 \%$ of respondents

- $\quad 54.7 \%$ of respondents

- $\quad 53.8 \%$ of respondents

- $\quad 46.2 \%$ of respondents

- $\quad 44.3 \%$ of respondents

- $\quad 43.4 \%$ of respondents

Group 2 of survey questions - assessment of individual experiences and quality of e-learning and hybrid learning in the framework of COVID-19 lockdown as compared to traditional, face-to-face learning formats - yielded the following representative results across the board. 
Respondents of all groups were asked to compare the individual experiences and estimations of quality and efficiency of traditional, face-to-face in-presence learning and hybrid or e-learning in the timeframe of the COVID-19 lockdown (respondents were instructed to disregard their individual assessment of blended learning or online learning prior to 2020).

The comprehensive comparison of individual experiences of traditional learning (TL) and e-learning (EL) was ranked according to the 5-Point Likert Scale (5-maximum quality and efficiency, 1 - minimum quality and efficiency). Students of Oriental and European languages programs of all levels in regional universities of Ukraine have ranked the comparative quality of traditional and e-learning in the following way: 1) 4 - mostly qualitative and efficient (TL $-48 \%$, EL $-40 \%$ of respondents); 2 ) 5 - most qualitative and efficient (TL $-28 \%$, EL $-26 \%$ of respondents); 3 ) 3 - average in quality and efficiency (TL $-20 \%$, $\mathrm{EL}-25 \%$ of respondents).

The average score of individual quality and efficiency comparison for traditional learning (TL) and e-learning (EL) by all groups of students in regional universities of Ukraine is 4 - mostly qualitative and efficient.

The students of all groups were prompted to contrast their individual assessment e-learning and hybrid learning against the prior to COVID-19 timeframe paradigm of experience of traditional in-presence learning. In-presence learning (TL) was estimated as a conventional $100 \%$ of potential quality of education process and learning outcomes for European and Oriental languages programs. Accordingly, the respondents were to scale their assessment of e-learning and hybrid learning quality from $0 \%$ (no correspondence to TL quality in individual experience) to $100 \%$ (full correspondence to TL quality in individual experience) in $10 \%$ increments.

The geographic distribution of contrastive assessment of e-learning and hybrid learning quality by students across regional centers of Ukraine yielded the following results (Figure 4):

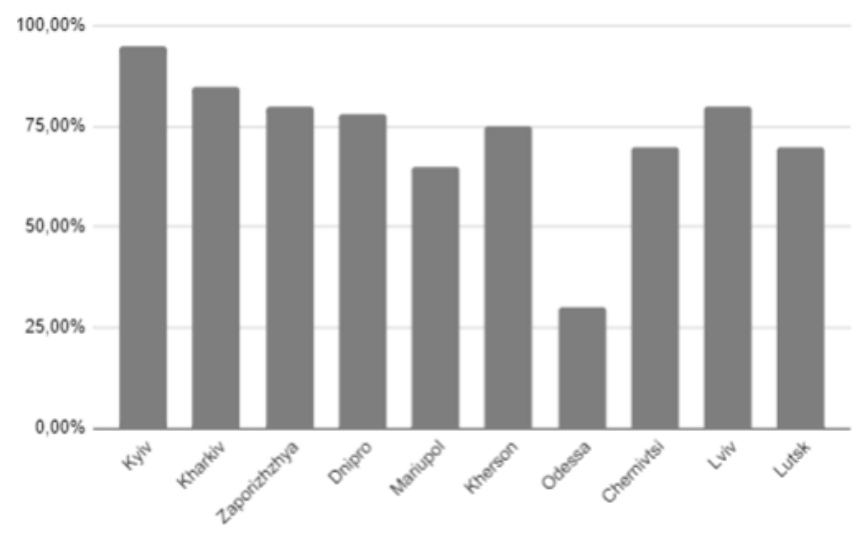

Figure 4. Distribution of contrastive assessment of e-learning and hybrid learning quality by students in regional cities of Ukraine

According to survey data of students of Oriental and European languages programs of all levels in regional universities of Ukraine (excluding the capital city of Kyiv), e-learning and hybrid learning satisfaction in the timespan of COVID-19 scores the highest quality approximation to traditional learning in such regional centers as: Kharkiv (East) - 85\% comparative score to TL; Lviv (West) - 80\% comparative score to TL; Zaporizhzhya (South) - 80\% comparative score to TL; Dnipro (South-East) - 78\% comparative score to TL.

Group 3 of survey questions - individual quality assessment of learning process design, programmed learning outcomes and projected competencies for university programs of European (English, French, Spanish, Italian) and Oriental (Mandarin Chinese, Japanese) languages in the framework of COVID-19 lockdown and quarantine measures (March 2020 - January 2021) - yielded the following representative results across the board.

Respondents of all groups were prompted to assess the degree of adaptation efficiency of each element of educational process, heretofore identified as conductive to quality of e-learning and hybrid learning format in the framework of COVID-19 (Figure 16). The scale of 5 (most efficiently adapted for e-learning and hybrid learning format) to 1 (least efficiently adapted for e-learning and hybrid learning format) was applied. 
Students of Oriental and European languages programs of all levels in regional universities of Ukraine have identified the following elements of the educational process and management as ranking highest (5 - most efficiently adapted for e-learning and hybrid learning format): Conducting lectures (54\% of respondents); Organization of independent work of students (42\% of respondents); Assessment (35\% of respondents); Conducting practical classes (34\% of respondents); Development of training materials and materials for assessment (34\% of respondents).

Qualitative content analysis of the individual experiences of students of Oriental and European languages programs of all levels in regional universities of Ukraine through hybrid and e-learning was conducted via the Voyant Engine (https://voyant-tools.org/) - a family of digital cloud-based corpus and text-mining tools. Respondents were, in particular, asked to submit three free-ranging concepts each that are individually evocative of hybrid and e-learning through the COVID-19 pandemic timespan. The concepts and associations were originally supplied by respondents in their native languages (Ukrainian and Russian).

The key concepts, thematically foregrounded in the corpus sample, that designate individual experiences of students Oriental and European languages programs of all levels in regional universities of Ukraine are (Figure 5): TIME; WORK; CONVENIENCE; LACK; SCHEDULE; COMMUNICATION; STRESS.

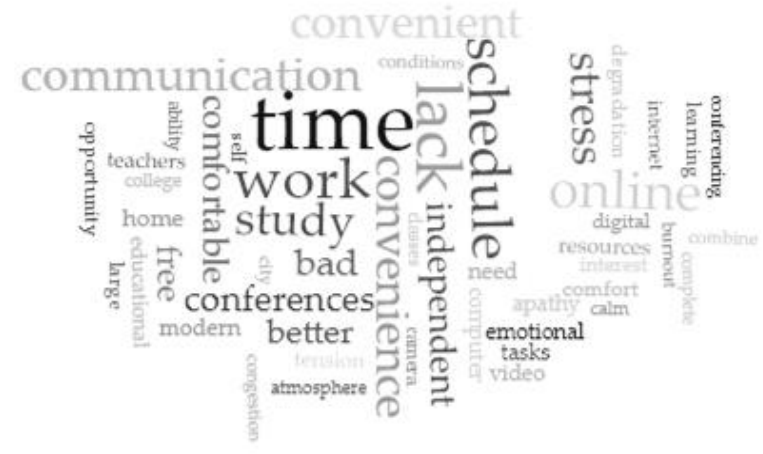

Figure 5. Foregrounding content analysis of individual e-learning and hybrid learning experinces of students of Oriental and European languages programs in regional universities of Ukraine

Terms and notions, associated by students of regional universities with individual experiences of e-learning and hybrid learning that demonstrate absolute frequency per corpus sample and relative frequency per corpus segments are: online (frequency index 0.12); time (frequency index - 0.078); lack (frequency index - 0.039); schedule (frequency index - 0.039); work (frequency index -0.039).

It bears pointing out that of the thematic concepts foregrounded across the sample by students of Oriental and European languages programs in regional universities of Ukraine two bear negative connotations - LACK and STRESS. Only the term LACK demonstrates both absolute and relative frequency in the assessment of individual experiences and quality of e-learning and hybrid learning by students of regional universities.

The proportionately frequent collocations of the notion LACK in subjective quality assessment of hybrid and e-learning experiences by students of Oriental and European languages programs in regional universities of Ukraine are (Figure 16): 1) LACK $=>(\mathrm{of})=.>$ communication; 2) LACK $=>(\mathrm{of})=.>$ convenience; 3) LACK $=>(\mathrm{of})=.>$ digital/online connection; 4) $\mathrm{LACK}=>(\mathrm{of})=.>$ resources; 5) LACK $=>(\mathrm{of})=.>$ teacher/mentor.

Respondents of all groups were prompted to identify the key challenges that impaired effective and qualitative adaptation of learning process design into the hybrid and digital distant format. The following generic types of impediments were derived from the individual experiences of Oriental and European languages programs students in the timeframe of COVID-19 in regional universities of Ukraine:

- Cluster 1 - Social and psychological: Emotional burnout; Stress; Fatigue; Health; Domestic difficulties/limitations; Time restrictions in connection with the introduction of quarantine restrictions;

- $\quad$ Cluster 2 - Technical challenges and digital literacy: Technical difficulties (lack of stable Internet connection, lack of necessary equipment, capacity of household computer equipment); Lack of digital literacy skills; Lack of experience in transforming the curriculum and training materials into an online format; Lack of digital communication experience; Lack of experience with electronic 
learning management systems (Moodle, Google Class, etc.); Lack of experience with auxiliary ICT tools for organizing the learning process (video conferencing, testing, surveys, online boards, etc.);

- Cluster 3 - Soft skills: Lack of skills of adaptation and self-organization; Lack of situational learning and training skills; Lack of communication and cooperation skills.

Students of Oriental and European languages programs of all levels in regional universities of Ukraine have identified the following top-scoring challenges and limitations (technical and socio-psychological) in efficient and qualitative transformation of educational elements into hybrid and e-learning format in their individual experience: 1) Technical difficulties (68\% of respondents) - Technical challenges and digital literacy cluster; 2) Fatigue (59.6\% of respondents); Emotional burnout (45.2\% of respondents); Stress (45.2\% of respondents) - Social and psychological cluster.

\subsection{Discussion}

The assessment of the overall individual satisfaction with e-learning and hybrid learning experience on Oriental and European Languages programs by students of regional universities of Ukraine is average to mostly agreeable.

The survey results for university students of Oriental and European languages in regions of Ukraine across the board corroborate the overarching research hypothesis of there existing an observable variation in the individual perception of e-learning and hybrid learning quality of foreign languages acquisition programs by different groups of stakeholders in different regions of Ukraine and in the capital city due to an arrangement of different factors: educational (core competencies, soft skills proficiency), social and psychological (information fatigue, stress, community influence) and technological (digital literacy, digital divide, digital gap, pre-existing level of educational process digitization and e-learning experiences).

The comprehensive evaluation of contrastive individual experiences of students with traditional learning (TL) and e-learning (EL) format is informed to a great extent by accompanying social, educational, and technological factors that contributed to this results: satisfactory to high level of digitalization in surveyed universities (prior to quarantine measures); high level of blended learning implementation in the classrooms of European and Oriental languages surveyed; high level of digital literacy of students (individual and institutional); high level of international mobility prior to quarantine measures that informed implementation of e-learning techniques.

Common preferred features of e-learning and hybrid learning by all groups of students of Oriental and European languages programs of all levels in regional universities of Ukraine correspond directly to the framework soft skills (WEF 2020), identified as relevant for the job market of the 2021-2020 timespan flexibility, adaptability, active learning, time-management.

Among the challenges, that e-learning and hybrid learning introduced into university-level Foreign languages acquisition, the 'digital literacy' group proper features as relatively insignificant ( $>15 \%$ score) in individual experiences of students in regional universities of Ukraine. Such distribution of technical challenges estimation testifies to the phenomenon of digital gap (DGR 2019; WEF 2020), pervasive in various areas of educational activities in the framework of Covid-19 lockdown. That placed students as an age group, as mostly representatives of the "digital native" generation - term by M. Prensky (2001) - people born or grown up through early formative years into the digital society (1995 year of birth onwards), at a significant advantage in the hybrid and digital educational process through the implementation of emergency quarantine measures of 2020 and 2021.

\section{CONCLUSION}

The global pandemic and subsequent quarantine measures and restrictions have a significant influence on the structure and procedure of higher education workflow, which considerably informed the scope of individual experiences, projected outcomes, and estimated quality of higher education in the realm of Foreign languages acquisition in all regions of Ukraine. 
The survey results on the individual experiences and quality assessment of e-learning and hybrid learning in the framework of COVID-19 lockdown yield comprehensive data on the parameters and challenges of e-learning and hybrid learning transformation of Oriental and European languages programs, common for students of higher educational institutions of the regional scale and status across Ukraine.

Overall individual experiences and quality estimation of e-learning and hybrid learning in the framework of COVID-19 lockdown and quarantine measures (March 2020 - January 2021) for regional university programs of European (English, French, Spanish, Italian) and Oriental (Mandarin Chinese, Japanese) languages are assessed as mostly agreeable to most agreeable by all groups of students across educational levels.

The qualitative assessment of the e-learning and hybrid learning was conducted through the retrospective evaluation of respondents' individual experiences that helped identify the comparative coordinates of positive and negative dimensions of the latter. The invariant positive quality indicators for e-learning and hybrid learning across all groups of students surveyed are the opportunity for multitasking, digital skills improvement, and lack of commute expenditure. The invariant negative quality indicators for e-learning and hybrid learning across all groups of students surveyed across the regions of Ukraine are the lack of interpersonal communication, technical impediments, and psychological states (fatigue, burnout, stress).

The contrastive exposure of individual experiences and quality of e-learning and hybrid learning in the framework of COVID-19 lockdown against the backdrop of traditional, in-presence learning formats identify e-learning and hybrid learning as mostly to average comparative in quality across all regions of Ukraine. Regional distribution of contrastive assessment of hybrid and e-learning permits to further disclose social, economic, cultural, and political factors, that inform the overall success of educational formats adaptation for Oriental and European languages programs in different regions Ukraine.

Assessment of learning process design, programmed learning outcomes and projected competencies for university programs of Oriental (Mandarin Chinese, Japanese) and European (English, French, Spanish, Italian) languages in the framework of COVID-19 lockdown allowed to identify the types of challenges that impaired effective and qualitative adaptation of learning process design into hybrid and digital distant format as predominantly socio-psychological for students of all groups surveyed in regions of Ukraine.

The study limitations are in the scope of the indicative survey results, exemplifying the outlined subjective quality assurance dimensions of e-learning and hybrid learning implementation for Oriental and European languages programs in regional universities of Ukraine, induced by COVID-19 measures. The corroboration of student satisfaction measurement by objective quality assurance and learning outcomes data is limited due to the summative assessment results through the relevant timespan (grades, absolute and relative efficiency ratios) not being in open access in regional universities of Ukraine.

The perspectives of the inquiry include fine-tuned estimation of the in-depth subjective quality assessment and subsequent efficiency assessment of hybrid and e-learning in different regions of Ukraine; contrastive case studies of Oriental and European languages acquisition in emergency digital distance format adaptations in the COVID-19 timespan in universities of regional and national status; contrastive case studies and best practices of Oriental and European languages programs transformation to hybrid and e-learning format in countries of Europe and Asia upon the alleviation of COVID-19 restrictive measures.

\section{ACKNOWLEDGEMENT}

Empirical findings and survey procedures have been conducted under the auspices of the Integrated Research framework of Romance Languages and Typology Chair of Borys Grinchenko Kyiv University European Languages And Literatures Development In Cross-Communication Context (0116U006607) and the Integrated Research framework of Oriental Languages and Translation Chair of Borys Grinchenko Kyiv University Oriental Studies Development in the framework of Higher Education Internationalization (0116U007073).

\section{REFERENCES}

Almalki, S. 2016. Integrating Quantitative and Qualitative Data in Mixed Methods Research - Challenges and Benefits. Journal of Education and Learning, 5(3).

Bekele, T. A., 2010. Motivation and satisfaction in internet-supported learning environments: A review. Educational Technology \& Society, 13(2), pp. 116-127. 
Bolliger, D. U. \& Wasilik O., 2009. Factors influencing faculty satisfaction with online teaching and learning in higher education. Distance Education, 30(1), pp.103-116.

Boyarsky K., 2020. What is Hybrid Learning. eThink. Retrieved from: https://www.owllabs.com/blog/hybrid-learning

Costareie, S., 2011. Assuaring quality based on the assessment of learning outcomes. 5th International Technology, Education and Development. Conference (INTED) Mar. 07-09, 2011, pp. 3235-3236.

Crowe, A. R., 2007. Learning to teach with mobile technology: A teacher educator's journey. In M. van 't Hooft \& K. Swan (Eds.), Ubiquitous computing in education. Mahwah, New Jersey: Lawrence Erlbaum Associates, pp. 127-144.

Dillman, D. A., Smyth, J. D., Christian, Leah Melani, 2014. Internet, Phone, Mail and Mixed-Mode Surveys: The Tailored Design Method, 4th edition. John Wiley: Hoboken, NJ.

Dos Reis A., 2015. To Be a (Blended) Teacher in the 21st Century - Some Reflections. International Journal of Research in E-learning, 1(1), pp. 11-24.

DQ Global Standards Report, 2019. World's first global standard for digital literacy, skills and readiness launched by the Coalition for Digital Intelligence. Retrieved from: https://www.dqinstitute.org/ (accessed July 2020).

Duff C., 2020. Everything you need to know about education, technology and distance learning. eThink, Retrieved from: https://www.owllabs.com/blog/hybrid-learning

European Commission, 2020. European E-Competence Framework Guideline. Retrieved from: https://www.ecompetences.eu/ (accessed July 2020).

Handbook of Disease Burdens and Quality of Life Measures, 2010. Springer Science+Business Media, pp 4288-4288.

Law of Ukraine, 2019. On Higher Education. Retrieved from: https://zakon.rada.gov.ua/laws/show/1556-18\#Text (accessed July 2020).

Makhachashvili, R., Semenist, I., \& Bakhtina, A., 2020. Digital Skills Development And Ict Tools For Final Qualification Assessment: Survey Study For Students And Staff Of European And Oriental Philology Programs, Electronic Scientific Professional Journal "Open Educational E-Environment Of Modern University, (9), 2020, pp. 54-68. https://doi.org/10.28925/2414-0325.2020.9.5

Makhachashvili, R., Semenist, I., \& Bakhtina, A., 2020. ICT Tools and Practices for Final Qualification Assessment in the Framework of COVID-19 Lockdown, Innovative Educational Technologies, Tools and Methods for E-learning Monograph. University of Silesia in Katowice, Poland, Katowice, pp. 183-194.

Markova, T., Glazkova, I., \& Zaborova, E. 2017. Quality Issues of Online Distance Learning. Social and Behavioral Sciences, (237), pp. $685-691$.

Ni, A. Y., 2013. Comparing the effectiveness of classroom and online learning: Teaching research methods. Journal of Public Affairs Education, 2013, 19(2), 199-215.

Prensky, M. 2001. Digital Natives, Digital Immigrants. On the Horizon, Vol. 9 No. 5.

Salyers, V., Carter, L., Carter, A., Myers, S., \& Barrett, P., 2014. The search for meaningful e-learning at Canadian universities: A multi-institutional research study. The International Review of Research in Open and Distributed Learning, 15(6), 2014, 313-347.

Smyrnova-Trybulska, E., Kommers P. et al (Eds). 2019. Universities in the Networked Society. Springer.

Taleb, N., 2010. The Black Swan: The Impact Of The Highly Improbable (2nd ed.). London: Penguin. ISBN 978-0-14103459-1.

Thiessen J \& Ambrock V. 2011. Value Added - The Editor In Design And Development Of Online Courses. The Theory and Practice of Online Learning, AU Press, Athabasca University. Retrieved from: https://read.aupress.ca/read/thetheory-and-practice-of-online-learning/section/7b34c0dd-89ad-4280-9c95-137c1e2aa471\#ch11

Trentin G. 2010. Networked Collaborative Learning: Social Interaction and Active Learning. Springer.

Tu, Pierre N. V. 1994. Dynamical systems: an introduction with applications in economics and biology. Berlin New York: Springer.

Van 't Hooft, M., Swan, K., Lin, Y-M., \& Cook, D. 2007. What is ubiquitous computing? Ubiquitous Computing in Education, pp. 3-17.

Voorn, R. J., \& Kommers, P. A. 2013. Social media and higher education: introversion and collaborative learning from the student's perspective. International Journal of Social Media and Interactive Learning Environments, 1(1), pp. 59-73.

World Economic Forum, 2020. The Future of Jobs Report. Retrieved from: http://www3.weforum.org/docs/WEF_Future_of_Jobs_2020.pdf (accessed November 2020). 